\title{
Review of Atrophic Gastritis and Intestinal Metaplasia as a Premalignant Lesion of Gastric Cancer
}

\author{
Yo Han Park ${ }^{1}$, Nayoung Kim ${ }^{1,2}$ \\ 'Department of Internal Medicine, Seoul National University Bundang Hospital, Seongnam, ${ }^{2}$ Department of Internal Medicine and Liver Research \\ Institute, Seoul National University College of Medicine, Seoul, Korea
}

\begin{abstract}
Atrophic gastritis (AG) and intestinal metaplasia (IM) are the main precursor lesions of gastric cancer as the incidence of gastric cancer increases in the gastric mucosa involved with $A G$ and IM. The prevalence of $A G$ and IM vary depending on countries, even it represents diverse results in the same nation. Usually $A G$ is antecedent of $I M$ but the etiologies of $A G$ and $I M$ are not always the same. The sensitivity and specificity of diagnostic methods to detect $A G$ and IM are different. Furthermore, the management strategy of $A G$ and IM has not been established, yet. Helicobacter pylori infection has been proved as the most important cause of AG and IM. Thus the eradication of $H$. pylori is very important to prevent the progression to gastric cancer which is still placed in the high rank in morbidity and mortality among cancers. However, the reversibility of $A G$ and IM by eradication of $H$. pylori which was assumed to be certain by meta-analysis is; however, controversial now. Therefore, the understanding and early diagnosis of AG and IM are very important, especially, in high incidence area of gastric cancer such as Republic of Korea.
\end{abstract}

(J Cancer Prev 2015;20:25-40)

Key Words: Atrophic gastritis, Helicobacter pylori, Intestinal metaplasia, Gastric cancer

\section{INTRODUCTION}

Gastric cancer remains the second most frequent cause of cancer-related deaths and ranks 4 th in cancer incidence worldwide. ${ }^{1}$ In Republic of Korea, gastric cancer is the second most common cancer followed by thyroid cancer and the third cause of cancer-related death followed by lung and liver cancer in the database of 2013 . $^{2}$ The prognosis of gastric cancer varies depending on stages. The 5-year survival rates for advanced gastric cancer are less than $20 \%$. On the contrary, early gastric cancer (EGC) makes a good prognosis that the 5 -year survival rates are over $90 \%$ to $95 \%$. $^{3-5}$ Therefore, it is important to individualize the management for high risk group of gastric cancer. The risk factors of gastric cancer are Helicobacter pylori infection, salt intake, smoking, alcohol, family history of gastric cancer, atrophic gastritis (AG), and intestinal metaplasia (IM) ${ }^{6}$ Particularly AG and
IM are considered to be premalignant lesions of gastric cancer. ${ }^{6}$ For this reason effective diagnosis and management of AG and IM is a very important research topic to prevent gastric cancer. ${ }^{7-9}$ According to a recent meta-analysis, the incidence rates of AG are in a wide range from $0 \%$ to $10.9 \%$ per year. ${ }^{10}$ This wide range of incidence of AG could be explained by the different settings in which the diagnoses of AG were made. ${ }^{10} H$. pylori infection is the most important risk factor of AG and IM. AG is considered to be an antecedent to IM. ${ }^{11}$ Thus the risk factors for AG are expected to be similar to those for IM. However, bacterial factors have been found to play an important role for AG while environmental and host factors are more important for IM. ${ }^{11}$ From this background, the aim of this review is to provide comprehensive information regarding the epidemiology, etiology, diagnosis and management of AG and IM, which will lay a foundation to establish strategies to prevent gastric cancer.

Received March 1, 2015, Revised March 18, 2015, Accepted March 18, 2015

Correspondence to: Nayoung Kim

Department of Internal Medicine, Seoul National University Bundang Hospital, 82 Gumi-ro 173 beon-gil, Bundang-gu, Seongnam 463-707, Korea Tel: +82-31-787-7008, Fax: +82-31-787-4051, E-mail: nayoungkim49@empas.com, ORCID: Nayoung Kim, http://orcid.org/0000-0002-9397-0406

Copyright (C) 2015 Korean Society of Cancer Prevention

(c) This is an Open Access article distributed under the terms of the Creative Commons Attribution Non-Commercial License (http://creativecommons. org/icenses/by-nc/3.0) which permits unrestricted non-commercial use, distribution, and reproduction in any medium, provided the original work is properly cited. 


\section{ATROPHIC GASTRITIS AND INTESTINAL METAPLASIA AS PRECURSOR LESIONS OF GASTRIC CANCER}

Chronic inflammation can damage inflamed cells and trigger a multistep process of carcinogenesis. In premalignant tissues associated with chronic inflammation, tumor cells and leukocytes of various kinds such as neutrophils, macrophages, monocytes, mast cells, eosinophils, dendritic cells, and lymphocytes are present. ${ }^{12.13}$ These inflammatory cells contribute to cancer initiation, promotion and metastasis by producing cytokines, reactive oxygen species, and reactive nitrogen species. Various oxidant products can damage cellular DNA, RNA, and proteins by chemical reactions such as oxidation, nitration, nitrosation, and halogenation. Damages of cellular components result in increased mutations and altered functions of important enzymes and proteins in premalignant tissues, so contributing to the multistage carcinogenesis process. ${ }^{14}$ According to the Correa model, chronic inflammation of gastric mucosa triggers a pathway of chronic active gastritis, multifocal atrophy, IM, gastric dysplasia and finally invasive gastric adenocarcinoma (Fig. 1). ${ }^{15}$ The pathogenesis of intestinal type gastric cancer can be explained by a multistep process from chronic gastritis through AG, IM, and dysplasia to cancer. The presence of AG, which has been traditionally defined as the loss of glands, ${ }^{16}$ is well known as a risk factor of gastric cancer. The risk of gastric cancer increases with greater extent and higher degree of gastric mucosal atrophy. ${ }^{17}$ Gastric IM is defined as the replacement of the surface, foveolar, and glandular epithelium in the gastric mucosa by intestinal epithelium with the presence of Paneth cells, goblet cells and absorptive cells. ${ }^{17}$ Several studies suggest that AG and IM are major precursor lesions of gastric cancer. ${ }^{18-20}$ These relationships

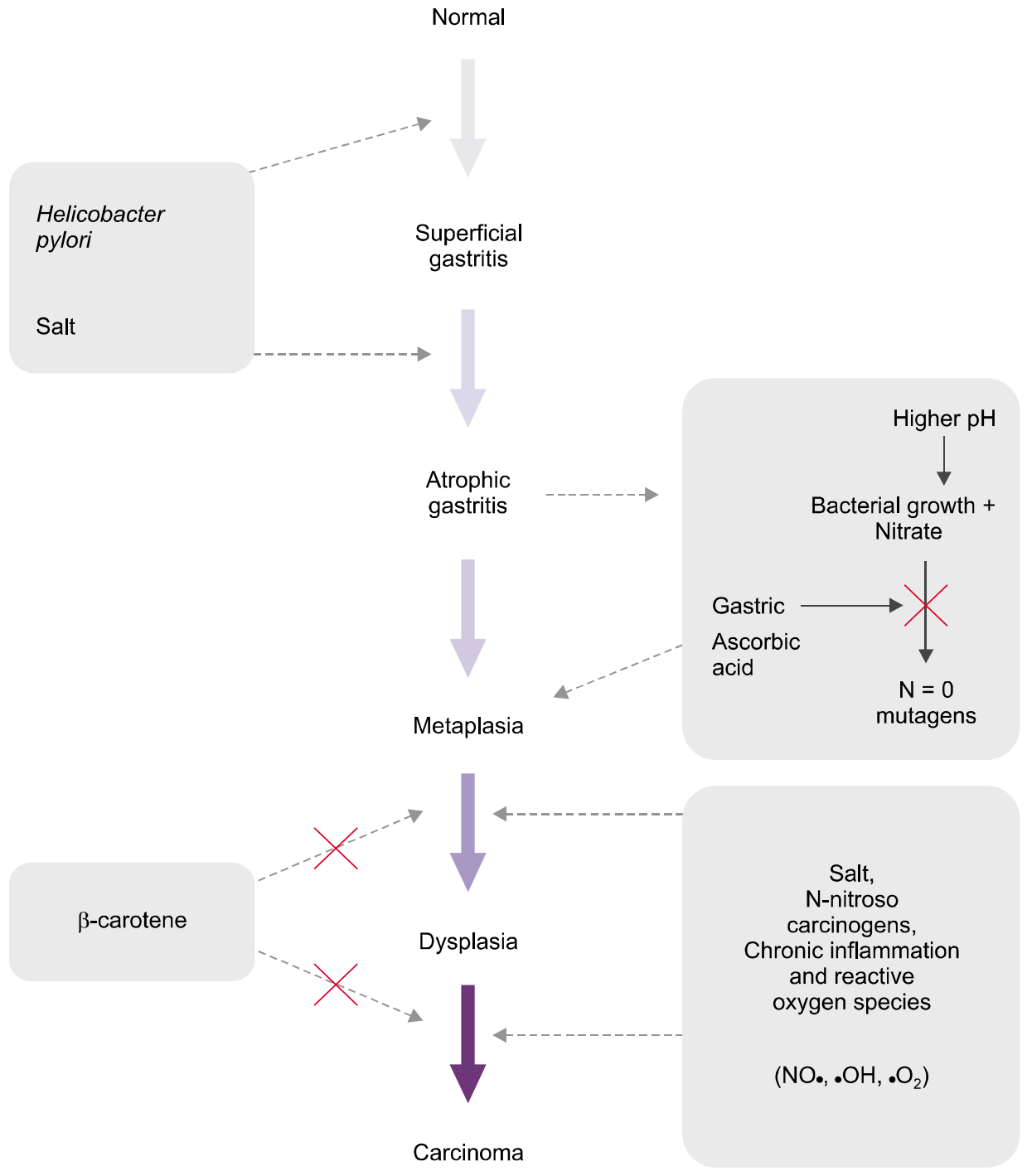

Figure 1. Correa's theory regarding human gastric carcinogenesis: a multistep and multifactorial process. Gastritis begins from superficial gastritis and progresses into atrophic gastritis, metaplasia, dysplasia and gastric cancer. Adapted from Correa et $\mathrm{al}^{15}$ 
were observed before the identification of $H$. pylori infection in $1982 .^{21}$ Gastric cancer divides into 2 major histologic types, intestinal-type and diffuse-type, by Lauren classification. ${ }^{22}$ The intestinal-type cancers are believed to arise secondary to AG and $\mathrm{IM}^{23}$ On the contrary, diffuse-type gastric cancer usually arises independently of IM. This raised doubts about the association between IM and gastric cancer development. ${ }^{24}$ It is thought that diffuse type is more likely to have a primary genetic etiology, and the involvement of $H$. pylori is probably limited to a subset of sporadic cases. ${ }^{23,24}$ However, many studies suggest that both intestinal and diffuse types of gastric carcinoma are associated with $H$. pylori infection. ${ }^{25,26}$ Compared with other risk factors of gastric cancer, AG and IM increase the risk of intestinal type gastric cancer exponentially. The risk of gastric cancer in subjects with severe fundal AG was 5.76 times higher than that in those having little or no fundal $\mathrm{AG}^{27}$ In addition, the subjects with IM have more than a 10-fold increased risk of developing gastric cancer. ${ }^{28}$ In addition, several groups have reported the correlation between $H$. pylori infection and gastric cancer. Moreover AG and IM, precursors of gastric cancer, elevate the risk of gastric cancer. ${ }^{18,19}$ In a prospective study of 1,526 subjects, 1,246 patients had $H$. pylori infection and 280 did not. ${ }^{18}$ During mean follow-up of 7.8 years, gastric cancer developed in individuals ( 36 patients, 2.9\%) infected with $H$. pyloribut not in the uninfected persons. ${ }^{18}$ Histological description of severe gastric atrophy, corpuspredominant gastritis, or IM are increasing risk factors of gastric cancer. ${ }^{18}$ In addition, in a cohort of 4,655 healthy asymptomatic subjects, the risk of gastric cancer increased stepwise from chronic atrophic gastritis (CAG)-free gastritis [H. pylori(+)/CAG (-) group] (hazard ratio [HR], 7.13; 95\% confidence interval [CI], 0.95 to 53.33 ) to CAG [H. pylori (-)/CAG(+) group] (HR, 14.85; $95 \% \mathrm{CI}, 1.96$ to 107.7 ) and finally to severe CAG with extensive IM [H. pylori(-)/CAG(+) group] (HR, 61.85; 95\% CI 5.6 to 682.64) in which $H$. pylori is lost. So it is probable that $H$. pylorialone is not directly associated with gastric carcinogenesis, ${ }^{19}$ but $H$. pyloriinduced chronic inflammation can provide the seed of cascade leading to gastric cancer, which can progress continuously even in the absence of $H$. pylori $^{29}$ The patients with $H$. pylori infection and IM have more than 6.4-fold increased risk of gastric cancer than the subjects of infected with $H$. pylori infection but without $\mathrm{IM}^{18}$ In a cohort study of 2,224 subjects conducted in Republic of Korea, the group with IM have 10.9-fold increased risk of gastric cancer. $^{20}$ Therefore, each lesion of AG or IM will increase the incidence of gastric cancer, and if both lesions are combined, the incidence of gastric cancer will increase even more. As mentioned above, H. pylori infection triggers a multistep progression from chronic gastritis, gastric atrophy, IM and finally into gastric cancer. $^{30}$ H. pylori was identified in 1982 by Marshall and Warren. ${ }^{31} H$. pylori is a gram-negative, flagellated bacterium about $3 \mu \mathrm{m}$ long with a diameter of about $0.5 \mu \mathrm{m} .{ }^{31} H$. pyloribecame the first bacterium to be classified as a type I carcinogen by International Agency for Research on Cancer (IARC) working group in $1994,{ }^{32}$ and now it is considered the most common etiologic bacterium of gastric cancer. ${ }^{1}$ Evidences supporting that came out from several meta-analyses. In a meta-analysis of 19 cohort or case-control studies, the summary odds ratio for gastric cancer in $H$. pylori-infected subjects is 1.92 (95\% CI, 1.32 to 2.78 ). ${ }^{33}$ In another meta-analysis of 42 cohort or case-control studies, the summary odds ratio for $H$. pylori infection in relation to gastric carcinoma was 2.04 (95\% CI, 1.69 to 2.45 ). ${ }^{34}$ So, these studies show the clear association between $H$. pylori and gastric adenocarcinomas. ${ }^{33.34}$ However, among $H$. pylori-positive patients, only $1 \%$ to $2 \%$ subjects will develop gastric cancer, ${ }^{17}$ suggesting that the final effects of $H$. pylori infection could be determined by prevalence, environmental factors, bacterial factors and host factors. ${ }^{35}$ Despite the clear relationship between $H$. pylori infection and gastric adenocarcinomas through AG and IM, especially in intestinal-type of gastric cancer, the mechanisms of process about chronic inflammation and developing gastric cancer are under investigation. The enhanced production of free radicals by chronic $H$. pylori infection causes mutations in target cells so the neoplastic clones are established. ${ }^{36}$ And tumor necrosis factor alpha from plays major roles in the growth, invasion and metastasis of neoplasm. This mechanism was called 'a perigenetic pathway'. ${ }^{36}$ Another study suggested that the TNF- $\alpha$ inducing protein (Tip $\alpha$ ) from $H$. pyloribinds to and enters the nucleus through a specific biding molecule, act as a carcinogen of gastric cancer. ${ }^{37}$

\section{PREVALENCE OF ATROPHIC GASTRITIS AND INTESTINAL METAPLASIA}

A meta-analysis of 14 studies on incidence of AG was reported in $2010,{ }^{10}$ of which the incidence rates of AG ranged from $0 \%$ to $10.9 \%$ per year. ${ }^{10}$ This wide range of incidence is explained by the particular settings in which the diagnosis of AG was made. ${ }^{10}$ The lowest incidence rates $(0 \%)$ were found in patients with reflux esophagitis and in patients successfully treated for $H$. pylori infection. ${ }^{38.39}$ The highest incidence rate (10.9\%) was observed in a study conducted in patients who underwent vagotomy for ulcer disease. $^{40}$ Regarding the $H$. pylori infection, the CAG incidence rate was higher in $H$. pylori-positive patients than in $H$. pylori- 
negative ones. ${ }^{10}$ In a meta-analysis, rate ratios comparing the incidence of AG in $H$. pylori positive patients to that in $H$. pylori negative ones ranged from 2.4 to 7.6 with a summary estimate of $5.0(95 \% \mathrm{CI}, 3.1$ to 8.3$){ }^{10}$ In contrast, reports on the incidence of IM are rare in asymptomatic general population, because upper gastrointestinal endoscopy with histological examination is needed to estimate the the prevalence of IM. In a study about the relationship between IM and $H$. pylori infection in the Netherlands, IM was found more often in $H$. pylori positive patients than in $H$. pylori negative ones $(33.9 \%$ vs. $15.2 \%, P<$ $0.001){ }^{41}$ The mean age of IM positive patients was 64 years and that of IM negative ones was 72 years $(P<0.005) .{ }^{41}$ In a Japanese prospective study with a follow-up of 7.8 years, IM was detected in as many as $37 \%$ of $1,426 \mathrm{H}$. pylori positive patients (mean age: 52.3 years) while in only $2 \%$ of 280 uninfected patients (mean age: 52.7 years).$^{18}$ There are several studies regarding prevalences of AG and IM in Republic of Korea. In a cohort study consisted of 389 subjects ( $\geq 16$ years), prevalences of AG in the antrum and corpus were $42.5 \%$ and $20.1 \%$, and prevalences of IM were $28.6 \%$ and $21.2 \%$, respectively. ${ }^{11}$ In another study reporting age-adjusted prevalence in Republic of Korea, the prevalence of AG was 42.7\% for men and $38.1 \%$ for women $(P=0.194)$ and that of IM was $42.5 \%$ for men and $32.7 \%$ for women $(P=0.005){ }^{42}$ The prevalence of AG and IM increases significantly with age for both men and women. ${ }^{42}$ A multicenter study of Republic of Korea in 2006, with 25,536 asymptomatic subjects assigned, evaluated that the prevalences of endoscopic AG and IM were $27.1 \%$ and $7.1 \%$, which were lower than those estimated with histologic diagnoses. ${ }^{43}$ The proportions of AG and IM in patients aged 40 years or less were $14.9 \%$ and $2.7 \%$, and in those aged 60 years or more were $43.5 \%$ and $12.3 \%$. This study showed that the prevalence of AG and IM increased significantly with age and male. ${ }^{43}$ The prevalences of endoscopic AG and IM were $40.7 \%$ and $12.5 \%$ in a multicenter study of 4,023 subjects in 2011, significantly higher than those of a multicenter study in 2006. ${ }^{44}$ In addition, the prevalences of AG and IM in males were still higher than those in females. ${ }^{44}$ This increase in prevalence of AG and IM may be attributed to aggressive diagnosis made by physicians in 2011 relative to 2006 rather than the real increase of prevalence rate of $\mathrm{AG}$ and $\mathrm{IM}^{44}$ The prevalence of $A G$ and IM varies $(9.4 \%$ to $63.8 \%$ in case of AG; $7.1 \%$ to $42.5 \%$ in case of IM) depending on diagnostic methods and countries (Table 1). ${ }^{11,42 \cdot 50}$

\section{RISK FACTORS OF ATROPHIC GASTRITS AND INTESTINAL METAPLASIA}

Several studies have investigated that dietary causes such as excessive salt intake, deficient ascorbic acid, and insufficient carotene could be risk factors of AG, IM, and gastric cancer. ${ }^{15.51}$ However, among the many risk factors, H. pylori infection is considered as the most important risk factor of AG and IM..$^{18-20.32}$ Especially, bacterial virulence genes such as cagA and VacA were found to be important risk factors of AG, IM, and gastric cancer. ${ }^{52.56}$ In a study of 58 subjects of $H$. pylori infection, with a mean follow-up period of 11.5 years, cagA was associated with a significantly increased risk of $\mathrm{AG}$ and IM (OR, 3.48; 95\% CI, 1.02 to 12.18). ${ }^{53}$ Infection with cagA-positive strains further increased the risk for gastric cancer by 1.64 (95\% CI, 1.21 to 2.24) overall in a meta-analysis. ${ }^{54}$ cagA proteins secreted by $H$. pylori translocate into cytoplasm of gastric mucosa cells via its type IV secretion system after $H$. pylori attachment. The cagA can interrupt signaling pathways by phosphorylation-dependent and independent mechanisms, leading to cytoskeletal change, motility, and abnormal proliferation in normal gastric epithelial cells. ${ }^{35} \mathrm{VaCA}$ is

Table 1. The prevalence of AG and IM in the world

\begin{tabular}{|c|c|c|c|c|c|}
\hline Author (year) & Country & Diagnostic methods & Study population (n) & AG (\%) antrum/body & IM (\%) antrum/body \\
\hline Kim et al. $(2008)^{11}$ & Korea & Histology & 389 & $42.5 / 20.1$ & $28.6 / 21.2$ \\
\hline Kim et al. $(2008)^{42}$ & Korea & Histology & 713 & $42.7 / 38.1$ & $42.5 / 32.7$ \\
\hline Park et al. $(2012)^{43}$ & Korea & Endoscopy & 25,536 & $27.1^{\mathrm{b}}$ & $7.1^{\mathrm{b}}$ \\
\hline Joo et al. $(2013)^{44}$ & Korea & Endoscopy & 4,023 & $40.7^{\mathrm{b}}$ & $12.5^{\mathrm{b}}$ \\
\hline Weck et al. $(2007)^{45}$ & Germany & Serology ${ }^{a}$ & 9,444 & $6.0^{\mathrm{b}}$ & - \\
\hline Borch et al. $(2000)^{46}$ & Sweden & Histology & 501 & $9.4^{\mathrm{b}}$ & - \\
\hline Asaka et al. $(2001)^{47}$ & Japan & Histology & 2,455 & $55.5^{\mathrm{b}}$ & $24.2^{\mathrm{b}}$ \\
\hline Zou et al. $(2011)^{48}$ & China & Histology & 1,022 & $63.8^{\mathrm{b}}$ & - \\
\hline Eriksson et al. $(2008)^{49}$ & Finland & Histology & 505 & - & $18.8 / 7.1$ \\
\hline Almouradi et al. $(2013)^{50}$ & USA & Histology & 437 & - & $15.0^{\mathrm{b}}$ \\
\hline
\end{tabular}

AG, atrophic gastritis; IM, intestinal metaplasia. ${ }^{a}$ Serology was test by Helicobacter pylori immunoglobulin G antibodies. ${ }^{\mathrm{b}}$ Prevalence of AG or IM in the antrum and/or body. 
another well-known virulence factor, $\mathrm{s} 1$ and $\mathrm{m} 1$ forms of VacAare more common in disease-associated $H$. pylori strains, and s $1 \mathrm{~m} 1$ genotype was related to gastric epithelial damage, AG and IM. $^{52,55.56}$ From a study of a total of $370 \mathrm{H}$. pylori-infected patients, a high association was observed between the presence of AG or IM and the prevalence of VacAs1, m1, cagA strains of $H$. pylori genotypes. ${ }^{56}$ Presence of atrophy was associated with VacAs1 (OR, 46.9; $95 \% \mathrm{CI}, 8.6$ to 256.4 ), VacAm1 (OR, 10.1; $95 \% \mathrm{CI}, 4.3$ to 23.7 ), and cagA (OR, 11.2; 95\% CI, 4.5 to 27.8). Similarly, presence of IM was associated with VacAs1 (OR, 14.9; 95\% CI, 4.2 to 53.2), VacAm1 (OR, 6.8; 95\% CI, 2.9 to 15.9), and cagA (OR, 4.8; 95\% CI, 2.1 to 10.6). ${ }^{56}$ Furthermore, other virulence factors such as $S a b A$ were also found and $S a b A$ (outer membrane protein) positive subjects is associated with AG, IM and gastric cancer. ${ }^{57}$

In a multicenter prospective study in Republic of Korea, risk factors of AG were $H$. pylori infection of antrum and corpus, cagA and VacAml positivity, age $\geq 61$ years. The risk factors of IMwere age $\geq 61$ years, $H$. pylori infection, strong spicy food, a smoking history and the presence of $I L 10592 \mathrm{C} / \mathrm{A}$ as against A/A. ${ }^{11}$ In conclusion, virulence factor of $H$. pylori was the most important risk factor of AG, while environmental or host factor were more important risk factors for IM. In another study on the risk factors of endoscopic AG and IM, the risk factors for AG were male sex, age groups of 40 to 59 years and $>60$ years, positive $H$. pylori serology, IM, and education below the college level (OR; 5.00, $2.55,1.38,1.41,4.29$, and 1.35, respectively). ${ }^{44}$ The risk factors for IM were male sex, AG, age groups of 40 to 59 years and $>60$ years, positive $H$. pylori serology, having relatives with gastric cancer, consumption of dairy products and education below the college level (OR; 3.25, 2.17, 3.16, 1.88, 3.68, 1.48, 1.40, and 1.47, respectively). ${ }^{44}$

Many studies show that the $\operatorname{Vac} A$ and $\operatorname{cag} A$ genotypes of $H$. pylori are not equally distributed over the world ${ }^{58-60}$ There are significant differences in $H$. pylori genotypes between populations from Asia, different parts of Europe, and North and South America. Given the geographic distribution of specific $H$. pylori genotypes, it could be speculated that there might be differences in incidence of gastric cancer. ${ }^{58-60}$

\section{CLASSIFICATION OF GASTRITIS AND INTESTINAL METAPLASIA}

There is no universally accepted classification of gastritis, although several classifications of gastritis have been proposed. The first classification based on histopathological examination of gastric mucosa collected by so-called blind biopsies and samples collected during surgical procedures was created by Schindler. ${ }^{61}$ Schindler ${ }^{61}$ described that gastritis was divided into a superficial gastritis (Fig. 2B) that may progress to AG (Fig. 2C) and IM (Fig. 2D) with time, which is different from normal (Fig. 2A). Additionally, Schindler ${ }^{61}$ proposed that there were different courses and prognoses of disease by the type of the gastritis. And a novel classification and grading of gastritis was devised by a group of experts at the 9th World Congress of Gastroenterology in Sydney,
A

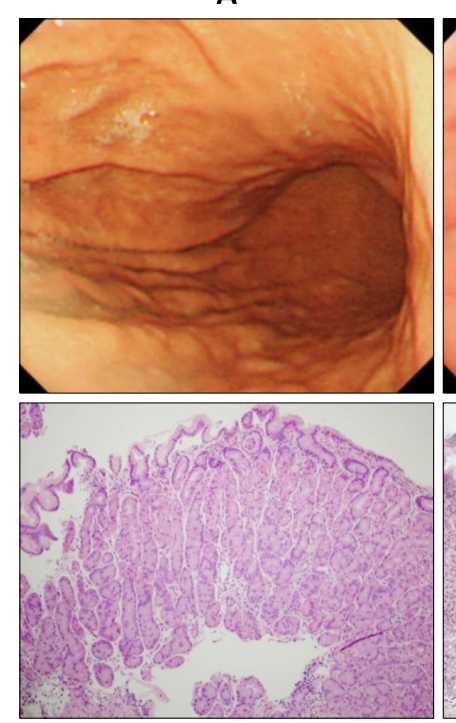

B

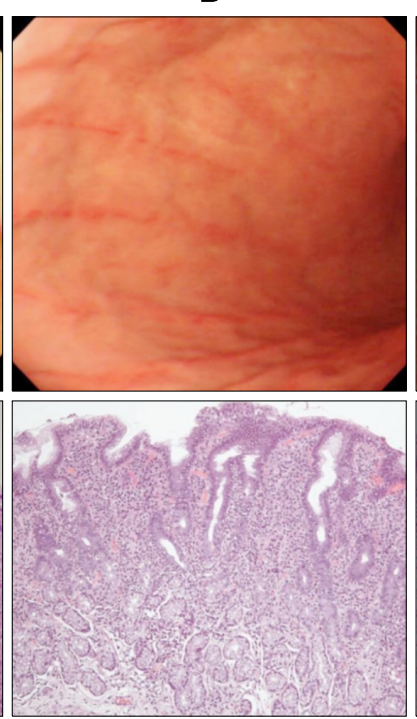

C
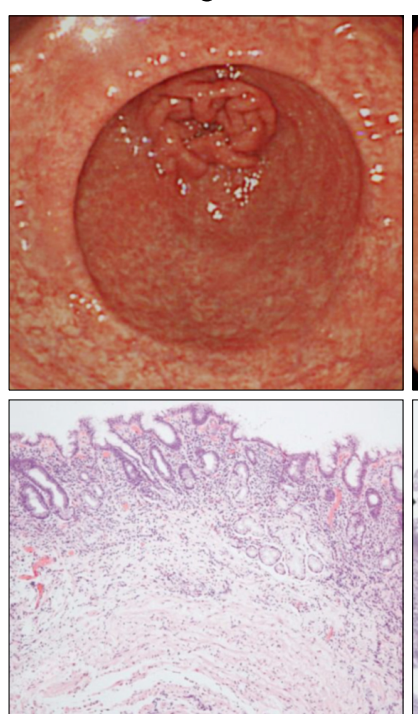

D

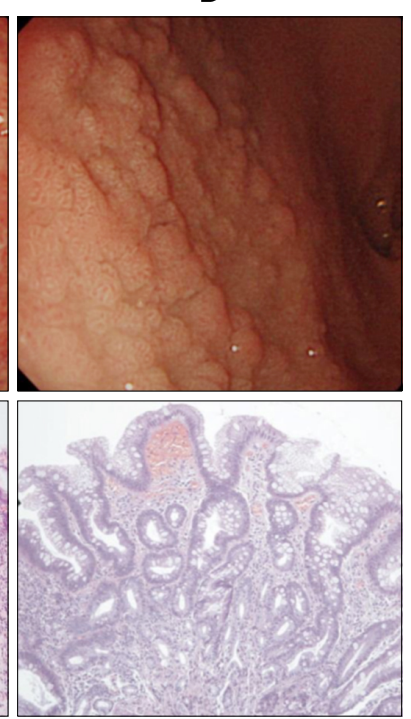

Figure 2. Classificataion of gastritis $(\mathrm{H} \& \mathrm{E}, \times 400)$. (A) Normal, (B) superficial gastritis, (C) atrophic gastritis, (D) intestinal metaplasia. Adapted from Schindler. ${ }^{61}$ 
1. Activity

neutrophil infiltration

2. Chronic inflammation mononuclear cell infiltration

3. Glandular atrophy

4. Intestinal metaplasia

5. Helicobacter pylori density
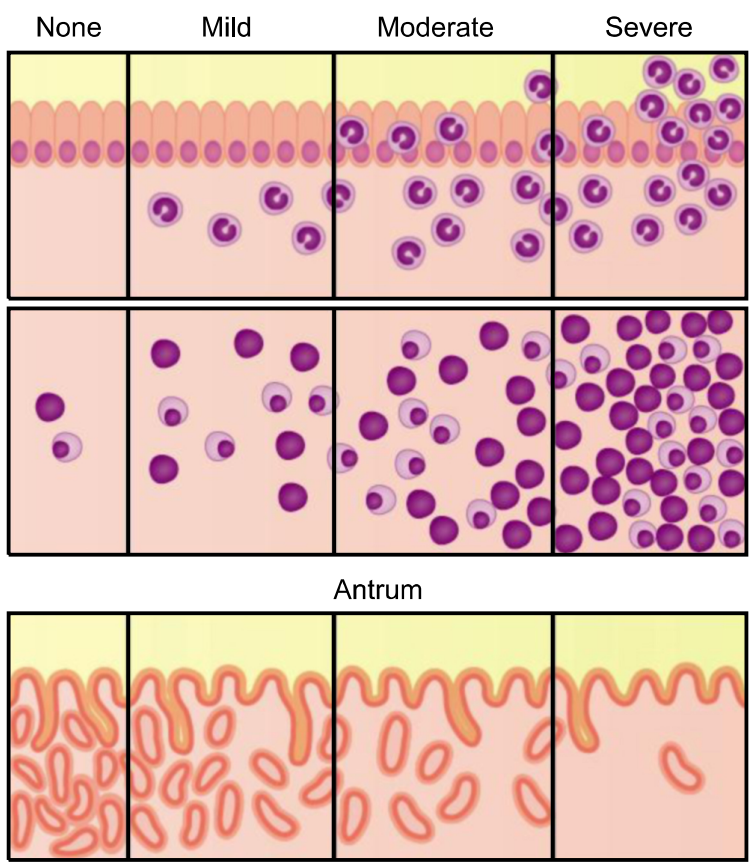

Corpus
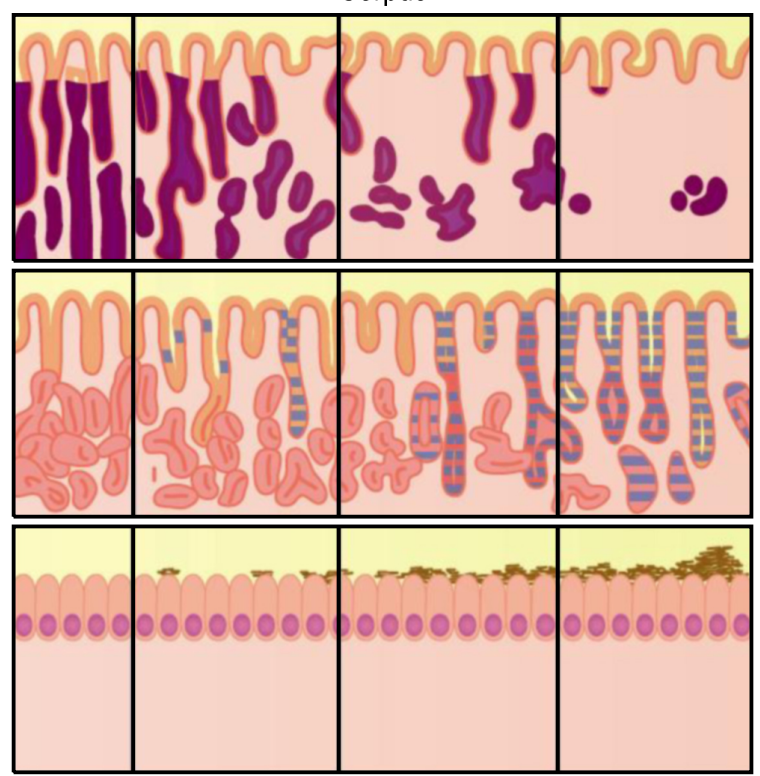

Figure 3. Grading of gastritis by Sydney System: acute inflammation, chronic inflammation, atrophic gastritis, intestinal metaplasia, and Helicobacter pylori densitiy. Adapted from Dixon et al. ${ }^{63}$
Australia in $1990 .^{62}$ The histological division of Sydney System is a practical guideline upon which the morphological features of gastritis in endoscopic biopsy samples should be documented. Type, severity and extent of gastric inflammation composed to possible etiology should be detailed depending on the chart. The Sydney System asserted the routine gastric biopsy sampling protocol (two from antrum and two from corpus, both from anterior and posterior walls) and sample fixation in adequately labelled separate containers. ${ }^{62}$ Now the updated Sydney system in 1996 is most widely used as the classification of gastritis. ${ }^{63}$ The original Sydney classification of gastritis dividing into gastritis acute, chronic and special forms, and grading of chronic inflammation, neutrophil activity, atrophy, IM and $H$. pylori density into mild, moderate and marked categories were kept. ${ }^{62}$ The updated Sydney system introduced a visual analogue scale for evaluating the severity of histological grading (Fig. 3). ${ }^{63}$ The histological features of the gastric mucosa were recorded using updated Sydney system scores, that is, $0=$ none, $1=$ mild, $2=$ moderate, and $3=$ marked. ${ }^{63}$ It changed the routine of endoscopic biopsy sampling by the introduction of biopsy sampling from the 
incisura angularis and modified corpus and antrum biopsy locations from the two opposite walls in lesser and greater curvature of both parts (Fig. 4). ${ }^{63}$ Endoscopic description of acute gastritis by Sydney system are divided into edema, exudates, erosions and hemorrhage. In contrast, endoscopic diagnosis and classification of chronic gastritis are reliable depending on the inter-observer. ${ }^{63}$

The updated Sydney system is the most widely used classification of gastritis. However, it does not reflect prognosis of gastric cancer risk in subjects with CAG. Therefore, the Operative Link on Gastritis Assessment (OLGA) was developed to improve the histological staging system for gastric atrophy. ${ }^{64}$ OLGA system uses gastric biopsy sampling protocol defined by Sydney System

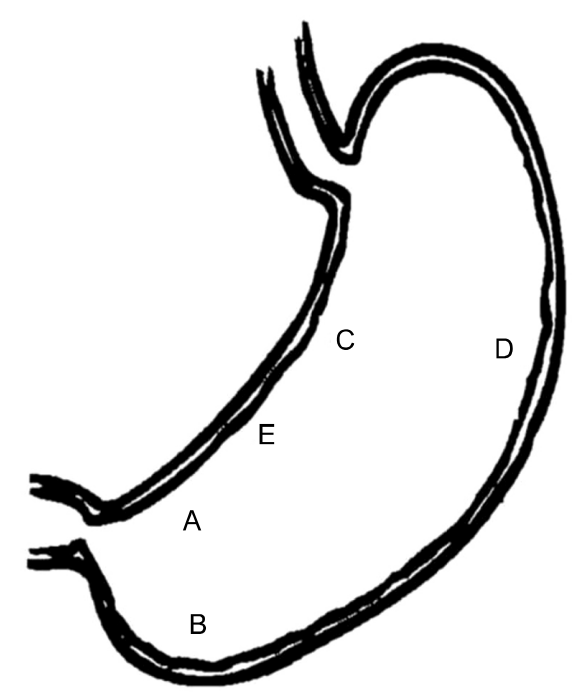

Figure 4. The optimal gastric biopsy sites recommend by updated Sydney system. Biopsy specimens are taken at five different sites. $A$, lesser curvature of the antrum; B, greater curvature of the antrum; C, lesser curvature of the corpus; D, greater curvature of the corpus; and E, incisura angularis. Adapted from Dixon et al. ${ }^{63}$ and the histological grading system recommended by the updated Sydney System (Fig. 5). ${ }^{64}$ Long-term follow-up studies with follow-up ranges from 144 to 204 months proved that the OLGA staging reflects relevant information on clinic-pathological outcome of gastritis and therefore $H$. pylori negative patients with low OLGA stages could be excluded from secondary preventive surveillance of gastric cancer. ${ }^{65}$ Whereas patients with higher OLGA stages (Stages III and IV) should be considered definitely candidates for endoscopic examination. ${ }^{65}$ However, there are no universally acceptable classification methods for gastritis, yet. For the optimization of the methods to interpret the gastritis, repetitive communication between the endoscopists and pathologists should be required.

IM could be classified according to the phenotype of mucin. Type I IM expresses only sialomucins, type III expresses sulfomucins and type II expresses a mixture of gastric and intestinal mucins. ${ }^{66}$ Several studies reported that type III or incomplete IM increase the risk of gastric cancer. ${ }^{67,68}$ However, a contrary result has been published. ${ }^{69}$ Furthermore, IM subtyping was not found to play a major role in the prediction of gastric cancer development in Republic of Korea. ${ }^{70}$ At the present time subtyping of IM is not recommended for clinical practice. ${ }^{71}$ However, a recent systemic review concluded that the incomplete IM was significantly related to the prevalence of gastric cancer. Moreover, it reported that the relative risks of gastric cancer were from 4- to 11-fold higher for the presence of incomplete type in comparison to complete type or in comparison to the absence of incomplete type. This systemic report concluded that subtyping of IM have the scientific evidence on the evaluation of gastric cancer risk. ${ }^{72}$

\section{DIAGNOSIS OF ATROPHIC GASTRITIS AND INTESTINAL METAPLASIA}

In most of previous studies about the clinical relevance of

\begin{tabular}{|c|c|c|c|c|c|}
\cline { 3 - 5 } \multicolumn{2}{c|}{} & \multicolumn{4}{c|}{ Corpus } \\
\cline { 2 - 6 } \multicolumn{2}{c|}{} & $\begin{array}{c}\text { No atrophy } \\
\text { (grade 0) }\end{array}$ & $\begin{array}{c}\text { Mild atrophy } \\
\text { (grade 1) }\end{array}$ & $\begin{array}{c}\text { Moderate atrophy } \\
\text { (grade 2) }\end{array}$ & $\begin{array}{c}\text { Severe atrophy } \\
\text { (grade 3) }\end{array}$ \\
\hline & $\begin{array}{c}\text { No atrophy } \\
\text { (grade 0) }\end{array}$ & Stage 0 & Stage I & Stage II & Stage II \\
\hline \multirow{2}{*}{$\begin{array}{c}\text { Mild atrophy } \\
\text { (grade 1) }\end{array}$} & Stage I & Stage I & Stage II & Stage III \\
\cline { 2 - 5 } & $\begin{array}{c}\text { Moderate atrophy } \\
\text { (grade 2) }\end{array}$ & Stage II & Stage II & Stage III & Stage IV \\
\hline & $\begin{array}{c}\text { Severe atrophy } \\
\text { (grade 3) }\end{array}$ & Stage III & Stage III & Stage IV & Stage IV \\
\hline
\end{tabular}

Figure 5. Gastritis staging: the OLGA system. Atrophy is defined as loss of appropriate glands (with or without metaplasia). In each compartment, atrophy is scored in a four-tiered scale (0-3) according to the visual analogue scale of th eupdated Sydney system. Adapted from Rugge et $\mathrm{al}^{64}$ 
endoscopic and histologic diagnosis of the gastritis, the diagnosis of gastritis should have been based on histological examination of the gastric mucosa. ${ }^{73,74}$ Especially in the young age group, a high index of suspicion of gastric atrophy is important, and confirmation of the diagnosis by histology is necessary. ${ }^{75}$ However in another study, endoscopic and histological diagnosis displayed high correlation. ${ }^{76}$ Particularly, the benefits of upper endoscopy to conform atrophic change of gastric mucosa are generally acceptied. ${ }^{77,78}$ Endoscopic features of AG is the visibility of a vascular pattern of gastric mucosa (Fig. $2 \mathrm{C}$ ) than normal gastric mucosa (Fig. 2A). Gastric IM (Fig. 2D) is defined as the replacement of the surface, foveolar, and glandular epithelium in the oxyntic or antral mucosa by intestinal epithelium. The endoscopic finding of IM is observed as a mucosal nodular pattern, usually occuring after the occurrence of the AG. It is not difficult to diagnose severe cases of AG and IM properly by endoscopic findings, but it is difficult to make the diagnoses of mild AG and $\mathrm{IM}^{75}$ Sometimes endoscopic diagnosis is not correlated to histological diagnosis. Therefore, it is proper to biopsy in suspected cases of AG and IM. However, atrophic mucosal changes are not distributed similarly in whole gastric mucosa. So multiple endoscopic biopsy of gastric mucosa does not always represent AG. Furthermore, it is difficult to take multiple biopsies of all subjects with simple gastritis. ${ }^{79,80}$ To resolve this clinical difficulty, noninvasive tests for precursor lesions such as serum level of pepsinogen (PG), gastrin-17 and H. pylori immunoglobulin $\mathrm{G}$ antibodies could be used as biomarkers of AG and IM to replace endoscopic biopsy. ${ }^{81}$ In the review, we discuss about three diagnostic methods for AG and IM; endoscopic, histological and PG I/II ratio.

\section{Endoscopic diagnosis of atrophic gastritis and intestinal metaplasia}

Endoscopic diagnosis of AG and IM is the basic method. However, there is the possibility of low sensitivity, specificity and inter-observer variation. Endoscopic diagnosis of AG is made when the visibility of a vascular pattern followed by loss of gastric mucosal gland is present (Fig. 2C). There are various criteria to endoscopic classification of atrophic gastritis. AG due to $H$. pylori infection is more common in the east and atrophic mucosal change progresses from antrum to the corpus along with lesser curvature (Fig. 6C), this endoscopic features reflect KimuraTakemoto classification well. ${ }^{82}$ The boundaries of the mucosal atrophy is called the F line (Fig. 6B), and AG is classified into six types. The closed-type AG indicates that the atrophic border remains on the lesser curvature, while the open-type AG means that the atrophic border no longer exists on the lesser curvature but extends along the anterior and posterior walls of the stomach (Fig. 6A). However, Western physicians lack a good understanding of Kimura-Takemoto classification because the ratio of autoimmune gastritis is greater in the West than in the East and $H$. pylori infection rate is rather low. ${ }^{83}$ In addition, the inter-observer reliability is rather low in Kimura-Takemoto classification from endoscopic features. Other limitation of the endoscopic diagnosis
A

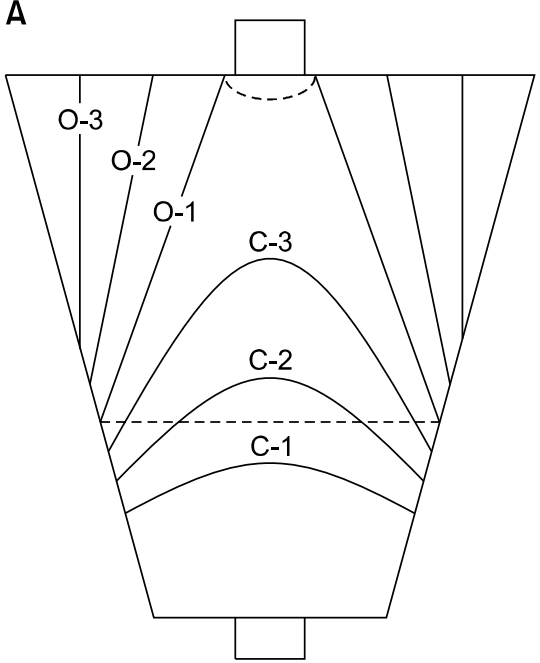

B

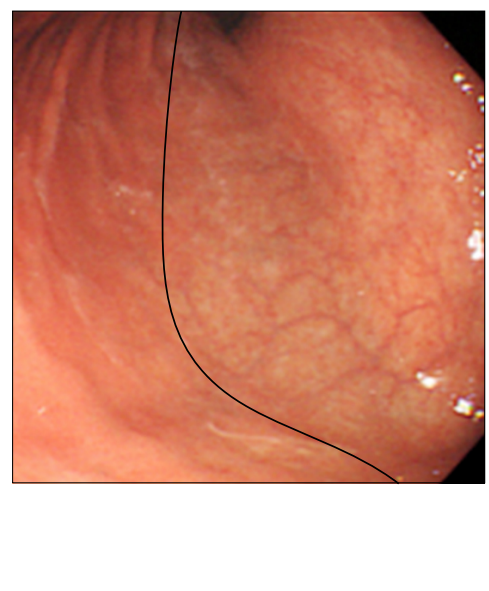

C

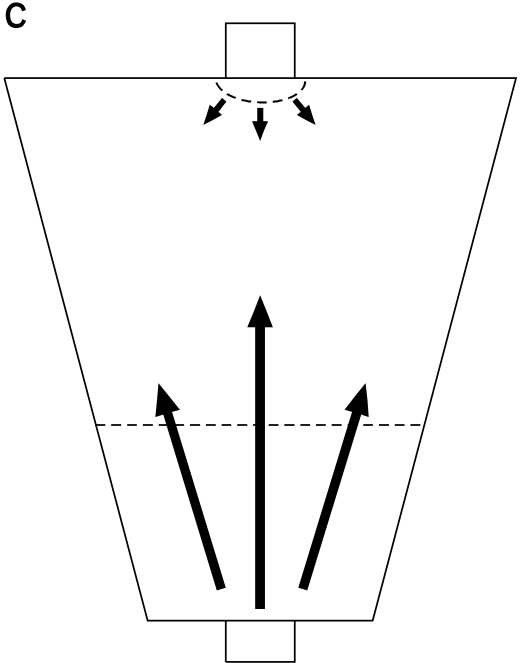

Figure 6. Kimura-Takemoto classification of chronic atrophic gastirits: (A) Atrophic gastritis (AG) is classified into six types. The closed-type AG indicates that the atrophic border remains on the lesser curvature of the stomach, while the open-type AG means that the atrophic border no longer exits on the lesser curvature but extends along the anterior and posterior walls of the stomach, (B) the boundaries of the mucosal atrophy is called the $\mathrm{F}$ line, (C) progression of atrophic mucosal change from antrum to the corpus along with lesser curvature. Adapted from Kimura and Takemoto. ${ }^{77}$ 
of AG and IM is the lower sensitivity and specificity than the pathological diagnosis. In the study of 1,333 subjects in Republic of Korea, the sensitivity of the prevalence of endoscopic diagnosis of atrophy was significantly low in age below 50 years old. ${ }^{75}$ The sensitivity and specificity of endoscopy for the diagnosis of gastric atrophy based on histological findings were $61.5 \%$ and $57.7 \%$ in the antrum, and were $46.8 \%$ and $76.4 \%$ in the corpus of the stomach. Especially endoscopic diagnosis of AG was inaccurate below 50 years of age because of mild atrophic mucosal change may look normal in endoscopy. ${ }^{75}$ In addition, the sensitivity and specificity of endoscopic IM diagnosis were also low in study by Lim et al. ${ }^{84}$ The sensitivity and specificity of endoscopic diagnosis of IM based on histology were $24.0 \%$ and $91.9 \%$ for the antrum and were $24.2 \%$ and $88.0 \%$ for the corpus. As indicated by a multivariate analysis, the activity of mucosal inflammation and the presence of endoscopic AG were associated with the sensitivity of endoscopic diagnosis of IM in the antrum, while benign gastric ulcers, dysplasia, and the presence of endoscopic AG were associated with the sensitivity of endoscopic diagnosis of IM in the corpus. ${ }^{84}$ Thus, a high level of suspicion is important to increase the sensitivity of endoscopic diagnoses of IM, especially when adenoma, endoscopic AG and ulcer are present, and confirmation of the doubt by histological diagnosis is necessary.

Other methods for endoscopic diagnosis of AG or IM are magnification chromoendoscopy and narrow band imaging (NBI). Several studies have suggested that chromoendoscopy with magnification could help to identify lesions of IM and dysplasia. ${ }^{85}$ However, high resolution magnifying endoscopy without chromoendoscopy also appears superior to standard endoscopy, allowing great accuracy for the diagnosis of $H$. pylori gastritis, IM, and dysplasia. ${ }^{86,87}$ The recent technology of NBI has been found to have good sensitivity and specificity for the diagnosis of gastric precancerous lesions. ${ }^{88,89}$ However, there is no agreement on which NBI patterns are associated with gastric precancerous lesions. So, further study is needed to apply NBI in diagnosis of AG and IM.

\section{Histological diagnosis of atrophic gastritis and intestinal metaplasia}

The second method of diagnosis of AG is histopathology. The updated Sydney system is the most widely accepted for classification and grading of gastritis. The updated Sydney system recommended five biopsies, two from the antrum, one from the incisura, and two from the corpus, because atrophic mucosal change and IM of gastric mucosa progress from antrum to body (Fig. 3). ${ }^{63}$ If it is difficult to obtain at these three points, biopsies from antrum and corpus are recommended. It is desirable to examine specimens from antrum and corpus of lesser and greater curvature, yet there are practical difficulties. Clinically, one biopsy specimen from lesser curvature and the other from greater curvature are used to evaluate AG and IM. . $^{73,84,90}$

Histological diagnosis is difficult when the specimens are inadequate. Deep portion of normal gastric mucosa are composed of different types of cells in antrum and body. Normal gastric mucosa of the antrum is composed of mucous glands which secrete gastric mucus, and that of the body is composed of parietal cell and chief cell which secrete gastric acid and digestive enzymes. Sometimes severe inflammation obscures the gland's population, making it impossible to assess mucosal atrophy reliably. Such cases can be labeled as 'indefinite for atrophy' and the final judgment can be deferred until the inflammation has regressed. In addition, the diagnosis of 'indefinite for atrophy' may be controversial among pathologists due to the difficulty in histological diagnosis. ${ }^{91}$ IM is defined as the replacement of the surface, foveolar, and glandular epithelium in the oxyntic or antral mucosa by intestinal epithelium. These IM has been subtyped by classification of mucin expression. There are several classification systems for IM. The most widely used and useful classification is was made by Jass and Filipe ${ }^{92}$ in 1981. Type I IM (complete) is positive for the sialomucin, and type II IM (incomplete) is positive for sialomucin in goblet and columnar cell. While, type III IM (imcomplete) is positive for sulphomucin. ${ }^{92}$ Complete type IM is similar to small intestine in pathologic features and tests positive for the MUC2 secreted by goblet cells. While, incomplete type IM is similar to large intestine in pathologic features, and positive for MUC5AC, MUC6 secreted by gastric mucosa and MUC2., ${ }^{70,93}$ In addition, high iron diaminealcian blue (HID-AB) stain can help classify the types of IM. Type I IM expresses only sialomucins (bright blue) (Fig. 7; type I) and type II, III expresses sialomucins (bright blue) and sulfomucins (black) (Fig. 7; type II and type III). ${ }^{70}$ Jass and Filipe ${ }^{92}$ reported that type III IM is associated with intestinal type gastric cancer. Other researchers have suggested that incomplete type IM is associated with gastric cancer. As such, it is still controversial discussing which type of IM is related with gastric carcinogenesis. ${ }^{67,68,70}$ In a cohort study of 861 subjects conducted in Republic of Korea, type III IM was associated with aging $(P=0.036)$, and type II IM was associated with gastric carcinogenesis in the presence of $H$. pylori infection $(P<0.05) .^{70}$

\section{Diagnosis by serum pepsinogen $\mathrm{I} / \mathrm{I}$ ratio}

The third diagnostic method of AG or IM is a measurement of 

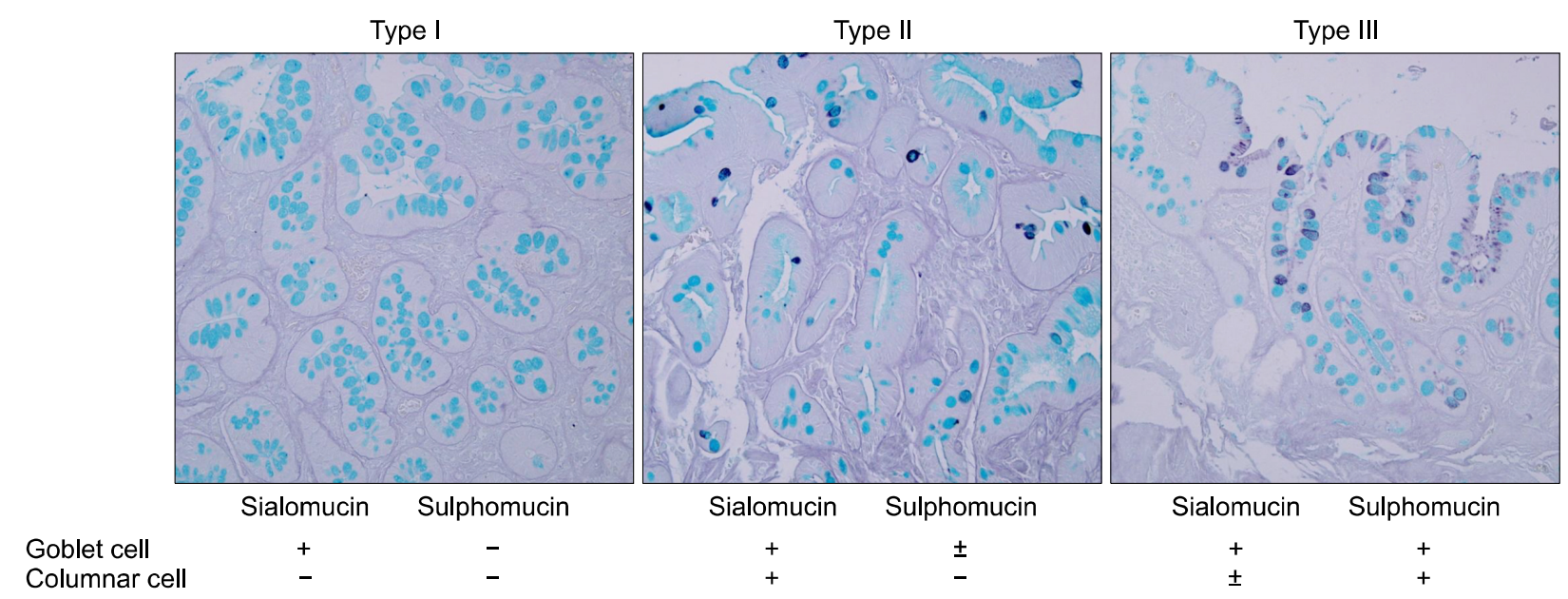

Figure 7. Phenotype of intestinal metaplasia (IM) classifying by mucin: type I IM expresses only sialomucins (bright blue) and type II, III expresses sialomucins (bright blue) and sulfomucins (black) (High iron diamine and alcian blue [pH 2.5] [HID-AB2.5] staining, $\times$ 400). Adapted from Kang et al. ${ }^{70}$

serum PG I, II and I/II ratio. The radioimmunoassay method is used to measure serum PG levels. Recently, a new method has emerged to measure PG level. ${ }^{94.95}$ The present methods to measure PG level are Latex-enhanced Turbidimetric Immunoassay (HBi Corp., Seoul, Korea; imported from Shima Laboratories, Tokyo, Japan), ${ }^{90.94 .95}$ and enzyme-linked immunosorbent assays (Biohit ELISA kit; Biohit, Helsinki, Finland) ${ }^{96.97}$ PG has been used to screen AG, IM and gastric adenocarcinoma for more than 20 years because of its non-invasiveness and cost-effectiveness. In Japan, PG screening for gastric cancer has been used to improve population compliance. ${ }^{98}$ However, $\mathrm{PG}$ screening is not accepted as a generalized screening method of AG or IM worldwide because of low positive predictive value in other countries. ${ }^{99}$

PG I is produced by chief cells in antrum and corpus, while PG II is produced by the chief cells and mucous neck cells of the whole gastric mucosa. When gastric atrophy develops, chief cells are replaced by pyloric glands, leading to a decrease in PG I level, while PG II levels is relatively unaffected, so a low PG I/II ratio reflect the severity of $\mathrm{AG}^{100,101}$ In a prospective study of 5,113 subjects in Japan, screening for gastric cancer with PG I $<70$ $\mathrm{ng} / \mathrm{mL}$ and PG I/II ratio $<3$ as the cut-off points had the sensitivity and specificity of $84.6 \%$ and $73.5 \%$, respectively. ${ }^{102}$ Generally PG I/II ratio 3.0 or less has been widely accepted as a cut-off value in several studies. ${ }^{103}$ However, in a recent Korean study which evaluated the relationship between PG level and AG, a new cut-off value of PG I/II ratio, 3.2, was suggested to diagnose $\mathrm{AG}^{90}$ The study suggested that serum PG I/II ratio remarkably decreased in correlation with the extent of atrophy by the Kimura-Takemoto classification. ${ }^{90}$ In another Korean research, PG I and PG II were negatively correlated with AG and only PG I/II ratio was positively correlated with AG. ${ }^{95}$ Serum PG I and PG II were higher in $H$. pylori-positive than in $H$. pylori-negative subjects, because a growth rate of PG II was higher than that of PG I in $H$. pylori positive individuals..$^{90,94,95}$

Moreover, a significantly positive correlation was found between age and the PG II $(P<0.001)$ and a negative correlation between age and the PG I/II ratio $(P<0.001)$. No correlation was found between age and the PG I. Men had significantly higher PG I levels compared with women $(P<0.001)$, and had a slightly higher PG II levels without statistical significance. These results suggest that the difference in the PG I levels observed between sex could be related to hormonal effects. ${ }^{95}$ Consequently these results show that multiple factors could change the serum PG level. Thus, the proper cut-off value of PG level would be necessary in order to increase sensitivity and specificity. ${ }^{90}$

\section{MANAGEMENT STRATEGY FOR ATROPHIC GASTRITIS AND INTESTINAL METAPLASIA}

Up to the present time, there are no unified clinical guidelines for prevention of gastric cancer regarding the classification of high-risk groups progressing to gastric cancer. ${ }^{104}$ However, through many studies, AG and IM are considered as precancerous lesions. Prevention and treatment of AG and IG could decrease the prevalence of gastric cancer. AG and IM could be managed by several strategies. H. pylori infection triggers a multistep progression from chronic gastritis, AG, IM and finally to invasive gastric cancer. ${ }^{30}$ To reduce the prevalence of gastric cancer, $H$. pylori eradication is a key step in management strategy. Another strategy is the surveillance to detect EGC in the subjects with AG 
or IM, with additional managements of several risk factors of AG and IM.

\section{Helicobacter pylori eradication}

H. pylori eradication is the basis of the treatment of AG and IM. However, it is still a controversial topic with a question if $H$, pylori eradication can improve gastric mucosa of AG and IM (Table 2). ${ }^{105-119}$ Several meta-analyses on correlation of $H$. pylorieradication and histologic improvement of AG and IM were reported in 2007. 2011 and 2014..$^{7-9}$ A meta-analysis of 8 articles in 2007, described that AG of antrum and corpus improved, but IM did not improve. ${ }^{7}$ Another meta-analysis of 12 articles in 2012 reported that AG of corpus improved, but AG and IM of antrum did not improve. ${ }^{8} H$. pylori eradication proved histological improvement of gastric mucosa in AG but no reversal of IM has been shown. Thus, IM was considered as a 'point of no return'. ${ }^{7.8}$ In contrast, a recent meta-analysis suggests that there were improvements in IM after H. pylorieradication. ${ }^{9}$ Meta-analysis of 16 articles in 2014, described that AG of antrum and corpus improved, IM of antrum improved but IM of corpus did not improve. ${ }^{9}$ At present, guidelines in Asia (China, Japan, and Korea) recommend $H$. pylori eradication in subjects with AG and IM. ${ }^{120-122}$ However, a study to prevent gastric cancer in Japan suggests that appropriate treatment time of $H$. pylori is younger age before the development of AG or IM. ${ }^{123}$ Because $H$. pylori eradication decreased the prevalence of gastric cancer only in patients without premalignant lesions like AG and IM. $^{18,124}$ Similarly in a Korean cohort study, the incidence of gastric cancer was 10.9 times higher in the subjects with IM, and the eradication of $H$. pylori could not reduce gastric cancer development in patients with $\mathrm{IM}^{20}$ So, the diagnosis and treatment of $H$, pylori infection in younger people before the development of AG and IM could be more effective strategy to prevent gastric cancer. Considering the positive results of the recent studies showing improvement of AG and IM by $H$. pylori eradication, it is expected to reduce the occurrence of gastric cancer. ${ }^{9}$ Therefore, further prospective studies are needed to determine the optimal strategy about $H$. pylori eradication to prevent gastric cancer.

\section{Screening for early detection of gastric cancer}

The 5-year survival rate of EGC was greater than $90 \% .{ }^{125}$ Moreover, surgery is no longer needed because of the recent advances in endoscopic resection techniques and technologies for EGC. ${ }^{126}$ Therefore, it is important to establish optimal screening methods in high gastric cancer prevalence area such as Republic of Korea and Japan. Republic of Korea and Japan have been conducting biennial screening of gastric cancer in general population over 40-years-of-age. ${ }^{127,128}$ However, optimal screening interval of gastric cancer is still under discussion. In a Japanese study, the 5-year survival rate was significantly higher in subjects who had undergone endoscopic examinations within 2 years before being diagnosed with gastric cancer than that of patients who had not $(96.5 \%$ vs. $71.0 \% ; P<0.01) .{ }^{129}$ However, the survival rates for a group of 1-year screening interval and a group of 2-year

Table 2. Histological parameters of AG and IM after Helicobacter pylori eradication

\begin{tabular}{|c|c|c|c|c|c|c|c|c|}
\hline \multirow[b]{2}{*}{ Author (year) } & \multirow[b]{2}{*}{ Country } & \multicolumn{2}{|c|}{ Study arms (n) } & \multirow{2}{*}{$\begin{array}{l}\text { Follow-up } \\
\quad(\mathrm{mo})\end{array}$} & \multicolumn{4}{|c|}{ Histologic parameters } \\
\hline & & Eradicated & $\begin{array}{c}\text { Not } \\
\text { eradicated }\end{array}$ & & antrum & corpus & antr & rpus \\
\hline Sung et al. $(2000)^{105}$ & China & 226 & 245 & 12 & Yes & Yes & Yes & Yes \\
\hline Kim et al. $(2000)^{106}$ & Korea & 41 & 16 & 24 & No & No & Yes & Yes \\
\hline Annibale et al. $(2000)^{107}$ & Italy & 5 & 7 & 6 & Yes & Yes & Yes & Yes \\
\hline Ohkusa et al. (2001) & Japan & 115 & 48 & $12-15$ & Yes & Yes & Yes & Yes \\
\hline Ruiz et al. $(2001)^{109}$ & Colombia & 29 & 21 & 72 & Yes & No & No & No \\
\hline Ito et al. $(2002)^{110}$ & Japan & 22 & 22 & 60 & Yes & Yes & Yes & Yes \\
\hline Annibale et al. $(2002)^{111}$ & Italy & 40 & 0 & $6-12$ & Yes & Yes & Yes & Yes \\
\hline Yamada et al. $(2003)^{112}$ & Japan & 87 & 29 & $10-50$ & Yes & Yes & Yes & Yes \\
\hline Iacopini at al. $(2003)^{113}$ & Italy & 10 & 0 & 12 & Yes & No & Yes & No \\
\hline Kamada et al. $(2003)^{114}$ & Japan & 37 & 8 & 36 & Yes & No & No & No \\
\hline Wambura et al. $(2004)^{115}$ & Japan & 107 & 118 & 12 & Yes & Yes & Yes & Yes \\
\hline Lahner et al. $(2005)^{116}$ & Italy & 38 & 36 & $48-137$ & Yes & Yes & Yes & Yes \\
\hline Lu et al. $(2005)^{117}$ & China & 92 & 87 & 36 & Yes & Yes & Yes & Yes \\
\hline Kamada et al. (2005) & Japan & 1,787 & 233 & 12 & Yes & Yes & Yes & Yes \\
\hline Toyokawa et al. $(2010)^{119}$ & Japan & 241 & 19 & 60 & Yes & Yes & Yes & Yes \\
\hline
\end{tabular}

AG, atrophic gastritis; IM, intestinal metaplasia. 
were not significantly different $(P=0.4595) .{ }^{129}$ These results have served as the basis for recommending that the optimal interval for screening of gastric cancer should be 2 years. Yet, optimal screening methods in high risk group of gastric cancer are still controversial. A recent Korean study in a subgroup of subjects with severe IM, EGC was more frequently observed in the 1-year interval screening group than the 2-year interval screening group $(66.7 \%$ vs. $35.5 \% ; P=0.047) .{ }^{130}$ Another Korean study conducted with the general population in a healthcare center reported that the proportion of EGC was higher in an annual screening group than in a biennial screening group (98.6\% vs. 80.7\%; $P<0.01$ ) and endoscopic resection was performed more frequently in the annual screening group $(56.9 \%$ vs. $33.3 \% ; P=0.02) .{ }^{131}$ This result also suggested that 1-year interval surveillance could be useful for high risk subjects with IM.

\section{Control of other risk factors}

Adequate consumption of vegetables and fruits seems to reduce the risk of cancer and decrease the incidence of gastric cancer in the West. Although some studies for premalignant gastric lesions have shown positive results of vitamin C, folic acid, and beta-carotene supplementation, though these results were not confirmed in a large meta-analysis. ${ }^{132-135} \mathrm{H}$. pylorieradication is the main strategy for prevention of gastric cancer in individuals with AG and IM, but it may be helpful to change diet and supply vitamin C, folic acid, and beta-carotene. Consequently, further large cohort study is needed to establish the optimal strategy of gastric cancer prevention.

\section{CONCLUSION}

Gastric cancer is still a major cause of death in Republic of Korea. To reduce the prevalence of gastric cancer, it is very important to classify and manage the high risk groups of gastric cancer. Furthermore, H. pylori infection triggers a multistep inflammation from chronic gastritis, atrophic gastritis, IM and finally to gastric cancer. Many studies have proved that AG and IM are precancerous lesions of gastric cancer. Diagnostic methods of AG and IM are endoscopic, histological findings and PG I/II ratio. Each method has advantages and disadvantages, and it is necessary to select the proper test according to the individual cases. As the infection of $H$. pylori is the most important risk factor of AG and IM it is important to perform $H$. pylori eradication to prevent the progression to gastric cancer. The appropriate time to prevent gastric cancer by $H$. pylorieradication is still under discussion. However, the most effective time point is before development of AG and IM. And it is difficult to know who will develop the AG and/or IM in the presence of $H$. pylori. $H$. pylori eradication had been known to improve AG histologically but not IM. However, a recent meta-analysis of IM after eradication of H. pylori reported the histological improvements even in cases of IM. In terms of early detection of gastric cancer 1-year interval of endoscopic screening for AG and IM could be superior in decreasing the prevalence of gastric cancer. Controlling other risk factors such as diet, vitamin C, beta-carotene and folic acid may be useful to decrease the prevalence of gastric cancer. However, further researches about the effect of $H$. pylori eradication, optimal screening interval and diet change, and various chemoprevention trials to prevent the development of gastric cancer are needed.

\section{ACKNOWLEDGMENTS}

This work was supported by the National Research Foundation of Korea (NRF) grant for the Global Core Research Center (GCRC) funded by the Korea government (MSIP) (No. 2011-0030001).

\section{CONFLICTS OF INTEREST}

No potential conflicts of interest were disclosed.

\section{REFERENCES}

1. Ferlay J, Shin HR, Bray F, Forman D, Mathers C, Parkin DM. Estimates of worldwide burden of cancer in 2008: GLOBOCAN 2008. Int J Cancer 2010;127:2893-917.

2. Statistics Korea. 2013. Daejeon, Statistics Korea. Available from: http://kostat. go.kr. Accessed December 3, 2014.

3. Yuasa N, Nimura Y. Survival after surgical treatment of early gastric cancer, surgical techniques, and long-term survival. Langenbecks Arch Surg 2005;390:286-93.

4. Park JM, Ryu WS, Kim JH, Park SS, Kim SJ, Kim CS, et al. Prognostic factors for advanced gastric cancer: stage-stratified analysis of patients who underwent curative resection. Cancer Res Treat 2006;38:13-8.

5. Hundahl SA, Phillips JL, Menck HR. The National Cancer Data Base Report on poor survival of U.S. gastric carcinoma patients treated with gastrectomy: fifth edition American Joint Committee on Cancer staging, proximal disease, and the "different disease" hypothesis. Cancer 2000;88:921-32.

6. Yoon H, Kim N. Diagnosis and management of high risk group for gastric cancer. Gut Liver 2015;9:5-17.

7. Rokkas T, Pistiolas D, Sechopoulos P, Robotis I, Margantinis G. The long-term impact of Helicobacter pylori eradication on gastric histology: a systematic review and meta-analysis. Helicobacter 2007;12 Suppl 2:32-8.

8. Wang J, Xu L, Shi R, Huang X, Li SW, Huang Z, et al. Gastric atro- 
phy and intestinal metaplasia before and after Helicobacter pylori eradication: a meta-analysis. Digestion 2011;83:253-60.

9. Kong YJ, Yi HG, Dai JC, Wei MX. Histological changes of gastric mucosa after Helicobacter pylori eradication: a systematic review and meta-analysis. World J Gastroenterol 2014:20:5903-11.

10. Adamu MA, Weck MN, Gao L, Brenner H. Incidence of chronic atrophic gastritis: systematic review and meta-analysis of follow-up studies. Eur J Epidemiol 2010;25:439-48.

11. Kim N, Park YS, Cho SI, Lee HS, Choe G, Kim IW, et al. Prevalence and risk factors of atrophic gastritis and intestinal metaplasia in a Korean population without significant gastroduodenal disease. Helicobacter 2008;13:245-55.

12. Balkwill F, Mantovani A. Inflammation and cancer: back to Virchow? Lancet 2001;357:539-45.

13. Coussens LM, Werb Z. Inflammation and cancer. Nature 2002; 420:860-7.

14. Ohshima H, Tazawa H, Sylla BS, Sawa T. Prevention of human cancer by modulation of chronic inflammatory processes. Mutat Res 2005;591:110-22.

15. Correa P. Human gastric carcinogenesis: a multistep and multifactorial process--First American Cancer Society Award Lecture on Cancer Epidemiology and Prevention. Cancer Res 1992:52:6735-40.

16. Correa P. Chronic gastritis: a clinico-pathological classification. Am J Gastroenterol 1988;83:504-9.

17. de Vries AC, Kuipers EJ. Epidemiology of premalignant gastric lesions: implications for the development of screening and surveillance strategies. Helicobacter 2007;12 Suppl 2:22-31.

18. Uemura N, Okamoto S, Yamamoto S, Matsumura N, Yamaguchi $\mathrm{S}$, Yamakido M, et al. Helicobacter pylori infection and the development of gastric cancer. N Engl J Med 2001;345:784-9.

19. Ohata H, Kitauchi S, Yoshimura N, Mugitani K, Iwane M, Nakamura $\mathrm{H}$, et al. Progression of chronic atrophic gastritis associated with Helicobacter pylori infection increases risk of gastric cancer. Int J Cancer 2004;109:138-43.

20. Kim N, Park RY, Cho SI, Lim SH, Lee KH, Lee W, et al. Helicobacter pylori infection and development of gastric cancer in Korea: long-term follow-up. J Clin Gastroenterol 2008;42: 448-54.

21. Correa P, Haenszel W, Cuello C, Tannenbaum S, Archer M. A model for gastric cancer epidemiology. Lancet 1975;2:58-60.

22. Lauren P. The two histological main types of gastric carcinoma: diffuse and so-called intestinal-type carcinoma. An attempt at a histo-clinical classification. Acta Pathol Microbiol Scand 1965;64:31-49.

23. Gore RM. Gastric cancer. Clinical and pathologic features. Radiol Clin North Am 1997:35:295-310.

24. Meining A, Morgner A, Miehlke S, Bayerdörffer E, Stolte M. Atrophy-metaplasia-dysplasia-carcinoma sequence in the stomach: a reality or merely an hypothesis? Best Pract Res Clin Gastroenterol 2001;15:983-98.

25. Handa Y, Saitoh T, Kawaguchi M, Misaka R, Ohno H, Tsai CR, et al. Association of Helicobacter pylori and diffuse type gastric cancer. J Gastroenterol 1996;31 Suppl 9:29-32.

26. Parsonnet J, Vandersteen D, Goates J, Sibley RK, Pritikin J, Chang Y. Helicobacter pylori infection in intestinal- and diffuse-type gastric adenocarcinomas. J Natl Cancer Inst 1991;83: 640-3.

27. Tatsuta M, Iishi H, Nakaizumi A, Okuda S, Taniguchi H, Hiyama
$\mathrm{T}$, et al. Fundal atrophic gastritis as a risk factor for gastric cancer. Int J Cancer 1993:53:70-4.

28. Leung WK, Sung JJ. Review article: intestinal metaplasia and gastric carcinogenesis. Aliment Pharmacol Ther 2002;16:1209-16.

29. Kato S, Matsukura N, Tsukada K, Matsuda N, Mizoshita T, Tsukamoto T, et al. Helicobacter pylori infection-negative gastric cancer in Japanese hospital patients: incidence and pathological characteristics. Cancer Sci 2007;98:790-4.

30. Siurala M, Varis K, Wiljasalo M. Studies of patients with atrophic gastritis: a 10-15-year follow-up. Scand J Gastroenterol 1966; 1:40-8.

31. Marshall BJ, Warren JR. Unidentified curved bacilli in the stomach of patients with gastritis and peptic ulceration. Lancet 1984:1:1311-5.

32. Schistosomes, liver flukes and Helicobacter pylori. IARC Working Group on the Evaluation of Carcinogenic Risks to Humans. Lyon, 7-14 June 1994. IARC Monogr Eval Carcinog Risks Hum 1994;61:1-241.

33. Huang JQ, Sridhar S, Chen Y, Hunt RH. Meta-analysis of the relationship between Helicobacter pylori seropositivity and gastric cancer. Gastroenterology 1998;114:1169-79.

34. Eslick GD, Lim LL, Byles JE, Xia HH, Talley NJ. Association of Helicobacter pylori infection with gastric carcinoma: a metaanalysis. Am J Gastroenterol 1999;94:2373-9.

35. Wroblewski LE, Peek RM Jr, Wilson KT. Helicobacter pylori and gastric cancer: factors that modulate disease risk. Clin Microbiol Rev 2010;23:713-39.

36. Tsuji S, Kawai N, Tsujii M, Kawano S, Hori M. Review article: inflammation-related promotion of gastrointestinal carcinogenesis-a perigenetic pathway. Aliment Pharmacol Ther 2003;18 Suppl 1:82-9.

37. Suganuma M, Yamaguchi K, Ono Y, Matsumoto H, Hayashi T, Ogawa $\mathrm{T}$, et al. TNF-alpha-inducing protein, a carcinogenic factor secreted from $\mathrm{H}$. pylori, enters gastric cancer cells. Int J Cancer 2008;123:117-22.

38. Kuipers EJ, Lundell L, Klinkenberg-Knol EC, Havu N, Festen HP, Liedman B, et al. Atrophic gastritis and Helicobacter pylori infection in patients with reflux esophagitis treated with omeprazole or fundoplication. N Engl J Med 1996;334:1018-22.

39. Tepes B, Kavcic B, Zaletel LK, Gubina M, Ihan A, Poljak M, et al. Two- to four-year histological follow-up of gastric mucosa after Helicobacter pylori eradication. J Pathol 1999;188:24-9.

40. Jönsson KA, Ström M, Bodemar G, Norrby K. Histologic changes in the gastroduodenal mucosa after long-term medical treatment with cimetidine or parietal cell vagotomy in patients with juxtapyloric ulcer disease. Scand J Gastroenterol 1988;23:433-41.

41. Craanen ME, Dekker W, Blok P, Ferwerda J, Tytgat GN. Intestinal metaplasia and Helicobacter pylori: an endoscopic bioptic study of the gastric antrum. Gut 1992;33:16-20.

42. Kim HJ, Choi BY, Byun TJ, Eun CS, Song KS, Kim YS, et al. The prevalence of atrophic gastritis and intestinal metaplasia according to gender, age and Helicobacter pylori infection in a rural population. J Prev Med Public Health 2008;41:373-9.

43. Park HK, Kim N, Lee SW, Park JJ, Kim JI, Lee SY, et al. The Distribution of Endoscopic Gastritis in 25,536 Heath Check-up Subjects in Korea. Korean J Helicobacter Up Gastrointest Res 2012;12:237-43.

44. Joo YE, Park HK, Myung DS, Baik GH, Shin JE, Seo GS, et al. Prevalence and risk factors of atrophic gastritis and intestinal 
metaplasia: a nationwide multicenter prospective study in Korea. Gut Liver 2013:7:303-10.

45. Weck MN, Stegmaier C, Rothenbacher D, Brenner H. Epidemiology of chronic atrophic gastritis: population-based study among 9444 older adults from Germany. Aliment Pharmacol Ther 2007;26:879-87.

46. Borch K, Jönsson KA, Petersson F, Redéen S, Mårdh S, Franzén LE. Prevalence of gastroduodenitis and Helicobacter pylori infection in a general population sample: relations to symptomatology and life-style. Dig Dis Sci 2000;45:1322-9.

47. Asaka M, Sugiyama T, Nobuta A, Kato M, Takeda H, Graham DY. Atrophic gastritis and intestinal metaplasia in Japan: results of a large multicenter study. Helicobacter 2001;6:294-9.

48. Zou D, He J, Ma X, Liu W, Chen J, Shi X, et al. Helicobacter pylori infection and gastritis: the Systematic Investigation of gastrointestinaL diseases in China (SILC). J Gastroenterol Hepatol 2011:26:908-15.

49. Eriksson NK, Kärkkäinen $\mathrm{PA}$, Färkkilä MA, Arkkila PE. Prevalence and distribution of gastric intestinal metaplasia and its subtypes. Dig Liver Dis 2008;40:355-60.

50. Almouradi T, Hiatt T, Attar B. Gastric Intestinal Metaplasia in an Underserved Population in the USA: Prevalence, Epidemiologic and Clinical Features. Gastroenterol Res Pract 2013:2013: 856256.

51. Stemmermann GN, Mower H. Gastritis, nitrosamines, and gastric cancer. J Clin Gastroenterol 1981;3(Suppl 2):23-7.

52. Atherton JC. The clinical relevance of strain types of Helicobacter pylori. Gut 1997:40:701-3.

53. Kuipers EJ, Pérez-Pérez GI, Meuwissen SG, Blaser MJ. Helicobacter pylori and atrophic gastritis: importance of the cagA status. J Natl Cancer Inst 1995;87:1777-80.

54. Huang JQ, Zheng GF, Sumanac K, Irvine EJ, Hunt RH. Meta-anal$y$ sis of the relationship between cagA seropositivity and gastric cancer. Gastroenterology 2003;125:1636-44.

55. Basso D, Zambon CF, Letley DP, Stranges A, Marchet A, Rhead JL, et al. Clinical relevance of Helicobacter pylori cagA and VacA gene polymorphisms. Gastroenterology 2008;135:91-9.

56. Nogueira C, Figueiredo C, Carneiro F, Gomes AT, Barreira R, Figueira $\mathrm{P}$, et al. Helicobacter pylori genotypes may determine gastric histopathology. Am J Pathol 2001;158:647-54.

57. Yamaoka Y. Increasing evidence of the role of Helicobacter pylori SabA in the pathogenesis of gastroduodenal disease. J Infect Dev Ctries 2008;2:174-81.

58. Yamaoka Y, Kodama T, Gutierrez O, Kim JG, Kashima K, Graham DY. Relationship between Helicobacter pylori iceA, cagA, and VacA status and clinical outcome: studies in four different countries. J Clin Microbiol 1999:37:2274-9.

59. Van Doorn LJ, Figueiredo C, Mégraud F, Pena S, Midolo P, Queiroz DM, et al. Geographic distribution of VacA allelic types of Helicobacter pylori. Gastroenterology 1999;116:823-30.

60. Kersulyte D, Mukhopadhyay AK, Velapatiño B, Su W, Pan Z, Garcia C, et al. Differences in genotypes of Helicobacter pylori from different human populations. J Bacteriol 2000;182:3210-8.

61. Schindler R. Chronic gastritis. Bull N Y Acad Med 1939;15: 322-37.

62. Misiewicz JJ. The Sydney System: a new classification of gastritis. Introduction. J Gastroenterol Hepatol 1991;6:207-8.

63. Dixon MF, Genta RM, Yardley JH, Correa P. Classification and grading of gastritis. The updated Sydney System. International
Workshop on the Histopathology of Gastritis, Houston 1994. Am J Surg Pathol 1996;20:1161-81.

64. Rugge M, Meggio A, Pennelli G, Piscioli F, Giacomelli L, De Pretis G, et al. Gastritis staging in clinical practice: the OLGA staging system. Gut 2007:56:631-6.

65. Rugge M, de Boni M, Pennelli G, de Bona M, Giacomelli L, Fassan M, et al. Gastritis OLGA-staging and gastric cancer risk: a twelve-year clinico-pathological follow-up study. Aliment Pharmacol Ther 2010;31:1104-11.

66. Correa P, Piazuelo MB, Wilson KT. Pathology of gastric intestinal metaplasia: clinical implications. Am J Gastroenterol 2010;105: 493-8.

67. Filipe MI, Muñoz N, Matko I, Kato I, Pompe-Kirn V, Jutersek A, et al. Intestinal metaplasia types and the risk of gastric cancer: a cohort study in Slovenia. Int J Cancer 1994:57:324-9.

68. Rokkas T, Filipe MI, Sladen GE. Detection of an increased incidence of early gastric cancer in patients with intestinal metaplasia type III who are closely followed up. Gut 1991;32:1110-3.

69. Conchillo JM, Houben G, de Bruïne A, Stockbrügger R. Is type III intestinal metaplasia an obligatory precancerous lesion in intestinal-type gastric carcinoma? Eur J Cancer Prev 2001;10:307-12.

70. Kang KP, Lee HS, Kim N, Kang HM, Park YS, Lee DH, et al. Role of intestinal metaplasia subtyping in the risk of gastric cancer in Korea. J Gastroenterol Hepatol 2009;24:140-8.

71. Dinis-Ribeiro M, Areia M, de Vries AC, Marcos-Pinto R, Monteiro-Soares M, O'Connor A, et al. Management of precancerous conditions and lesions in the stomach (MAPS): guideline from the European Society of Gastrointestinal Endoscopy (ESGE), European Helicobacter Study Group (EHSG), European Society of Pathology (ESP), and the Sociedade Portuguesa de Endoscopia Digestiva (SPED). Endoscopy 2012;44:74-94.

72. González CA, Sanz-Anquela JM, Gisbert JP, Correa P. Utility of subtyping intestinal metaplasia as marker of gastric cancer risk. A review of the evidence. Int J Cancer 2013;133:1023-32.

73. Jönsson KA, Gotthard R, Bodemar G, Brodin U. The clinical relevance of endoscopic and histologic inflammation of gastroduodenal mucosa in dyspepsia of unknown origin. Scand J Gastroenterol 1989:24:385-95.

74. Redéen S, Petersson F, Jönsson KA, Borch K. Relationship of gastroscopic features to histological findings in gastritis and Helicobacter pylori infection in a general population sample. Endoscopy 2003;35:946-50.

75. Eshmuratov A, Nah JC, Kim N, Lee HS, Lee HE, Lee BH, et al. The correlation of endoscopic and histological diagnosis of gastric atrophy. Dig Dis Sci 2010;55:1364-75.

76. Fung WP, Papadimitriou JM, Matz LR. Endoscopic, histological and ultrastructural correlations in chronic gastritis. Am J Gastroenterol 1979:71:269-79.

77. Kimura K, Takemoto T. An endoscopic recognition of the atrophic border and its significance in chronic gastritis. Endoscopy 1969;1:87-97.

78. Liu Y, Uemura N, Xiao SD, Tytgat GN, Kate FJ. Agreement between endoscopic and histological gastric atrophy scores. J Gastroenterol 2005:40:123-7.

79. Toukan AU, Kamal MF, Amr SS, Arnaout MA, Abu-Romiyeh AS. Gastroduodenal inflammation in patients with non-ulcer dyspepsia. A controlled endoscopic and morphometric study. Dig Dis Sci 1985;30:313-20.

80. Eriksson NK, Färkkilä MA, Voutilainen ME, Arkkila PE. The clin- 
ical value of taking routine biopsies from the incisura angularis during gastroscopy. Endoscopy 2005;37:532-6.

81. Cao Q, Ran ZH, Xiao SD. Screening of atrophic gastritis and gastric cancer by serum pepsinogen, gastrin-17 and Helicobacter pylori immunoglobulin G antibodies. J Dig Dis 2007:8:15-22.

82. Kimura K, Satoh K, Ido K, Taniguchi Y, Takimoto T, Takemoto T. Gastritis in the Japanese stomach. Scand J Gastroenterol Suppl 1996;214:17-20; discussion 21-3.

83. Neumann WL, Coss E, Rugge M, Genta RM. Autoimmune atrophic gastritis--pathogenesis, pathology and management. Nat Rev Gastroenterol Hepatol 2013;10:529-41.

84. Lim JH, Kim N, Lee HS, Choe G, Jo SY, Chon I, et al. Correlation between Endoscopic and Histological Diagnoses of Gastric Intestinal Metaplasia. Gut Liver 2013;7:41-50.

85. Dinis-Ribeiro M, da Costa-Pereira A, Lopes C, Lara-Santos L, Guilherme M, Moreira-Dias L, et al. Magnification chromoendoscopy for the diagnosis of gastric intestinal metaplasia and dysplasia. Gastrointest Endosc 2003;57:498-504.

86. Anagnostopoulos GK, Yao K, Kaye P, Fogden E, Fortun P, Shonde A, et al, High-resolution magnification endoscopy can reliably identify normal gastric mucosa, Helicobacter pylori-associated gastritis, and gastric atrophy. Endoscopy 2007;39:202-7.

87. Gonen C, Simsek I, Sarioglu S, Akpinar H. Comparison of high resolution magnifying endoscopy and standard videoendoscopy for the diagnosis of Helicobacter pylori gastritis in routine clinical practice: a prospective study. Helicobacter 2009;14:12-21.

88. Kadowaki S, Tanaka K, Toyoda H, Kosaka R, Imoto I, Hamada Y, et al. Ease of early gastric cancer demarcation recognition: a comparison of four magnifying endoscopy methods. J Gastroenterol Hepatol 2009:24:1625-30.

89. Capelle LG, Haringsma J, de Vries AC, Steyerberg EW, Biermann $\mathrm{K}$, van Dekken $\mathrm{H}$, et al. Narrow band imaging for the detection of gastric intestinal metaplasia and dysplasia during surveillance endoscopy. Dig Dis Sci 2010;55:3442-8.

90. Lee JY, Kim N, Lee HS, Oh JC, Kwon YH, Choi YJ, et al. Correlations among endoscopic, histologic and serologic diagnoses for the assessment of atrophic gastritis. J Cancer Prev 2014;19:47-55.

91. Rugge M, Correa P, Dixon MF, Fiocca R, Hattori T, Lechago J, et al. Gastric mucosal atrophy: interobserver consistency using new criteria for classification and grading. Aliment Pharmacol Ther 2002;16:1249-59.

92. Jass JR, Filipe MI. The mucin profiles of normal gastric mucosa, intestinal metaplasia and its variants and gastric carcinoma. Histochem J 1981;13:931-9.

93. Kang HM, Kim N, Park YS, Hwang JH, Kim JW, Jeong SH, et al. Effects of Helicobacter pylori Infection on gastric mucin expression. J Clin Gastroenterol 2008:42:29-35.

94. Kang JM, Kim N, Yoo JY, Park YS, Lee DH, Kim HY, et al. The role of serum pepsinogen and gastrin test for the detection of gastric cancer in Korea. Helicobacter 2008;13:146-56.

95. Kim HY, Kim N, Kang JM, Park YS, Lee DH, Kim YR, et al. Clinical meaning of pepsinogen test and Helicobacter pylori serology in the health check-up population in Korea. Eur J Gastroenterol Hepatol 2009;21:606-12.

96. Ren JS, Kamangar F, Qiao YL, Taylor PR, Liang H, Dawsey SM, et al. Serum pepsinogens and risk of gastric and oesophageal cancers in the General Population Nutrition Intervention Trial cohort. Gut 2009;58:636-42.
97. Ijijima K, Abe Y, Kikuchi R, Koike T, Ohara S, Sipponen P, et al. Serum biomarker tests are useful in delineating between patients with gastric atrophy and normal, healthy stomach. World J Gastroenterol 2009;15:853-9.

98. Miki K, Fujishiro M, Kodashima S, Yahagi N. Long-term results of gastric cancer screening using the serum pepsinogen test method among an asymptomatic middle-aged Japanese population. Dig Endosc 2009;21:78-81.

99. Ley C, Mohar A, Guarner J, Herrera-Goepfert R, Figueroa LS, Halperin D, et al. Screening markers for chronic atrophic gastritis in Chiapas, Mexico. Cancer Epidemiol Biomarkers Prev 2001;10:107-12.

100. Miki K, Ichinose M, Kawamura N, Matsushima M, Ahmad HB, Kimura $\mathrm{M}$, et al. The significance of low serum pepsinogen levels to detect stomach cancer associated with extensive chronic gastritis in Japanese subjects. Jpn J Cancer Res 1989:80:111-4.

101. Samloff IM, Varis K, Ihamaki T, Siurala M, Rotter JI. Relationships among serum pepsinogen I, serum pepsinogen II, and gastric mucosal histology. A study in relatives of patients with pernicious anemia. Gastroenterology 1982;83:204-9.

102. Yanaoka K, Oka M, Mukoubayashi C, Yoshimura N, Enomoto S, Iguchi $\mathrm{M}$, et al. Cancer high-risk subjects identified by serum pepsinogen tests: outcomes after 10-year follow-up in asymptomatic middle-aged males. Cancer Epidemiol Biomarkers Prev 2008; 17:838-45.

103. Dinis-Ribeiro M, Yamaki G, Miki K, Costa-Pereira A, Matsukawa M, Kurihara M. Meta-analysis on the validity of pepsinogen test for gastric carcinoma, dysplasia or chronic atrophic gastritis screening. J Med Screen 2004;11:141-7.

104. González CA, Agudo A. Carcinogenesis, prevention and early detection of gastric cancer: where we are and where we should go. Int J Cancer 2012;130:745-53.

105. Sung JJ, Lin SR, Ching JY, Zhou LY, To KF, Wang RT, et al. Atrophy and intestinal metaplasia one year after cure of $\mathrm{H}$. pylori infection: a prospective, randomized study. Gastroenterology 2000;119:7-14.

106. Kim N, Lim SH, Lee KH, Choi SE, Jung HC, Song IS, et al. Long-term effects of Helicobacter pylori eradication on intestinal metaplasia in patients with duodenal and benign gastric ulcers. Dig Dis Sci 2000;45:1754-62.

107. Annibale B, Aprile MR, D'ambra G, Caruana P, Bordi C, Delle Fave G. Cure of Helicobacter pylori infection in atrophic body gastritis patients does not improve mucosal atrophy but reduces hypergastrinemia and its related effects on body ECL-cell hyperplasia. Aliment Pharmacol Ther 2000;14:625-34.

108. Ohkusa T, Fujiki K, Takashimizu I, Kumagai J, Tanizawa T, Eishi $\mathrm{Y}$, et al. Improvement in atrophic gastritis and intestinal metaplasia in patients in whom Helicobacter pylori was eradicated. Ann Intern Med 2001;134:380-6.

109. Ruiz B, Garay J, Correa P, Fontham ET, Bravo JC, Bravo LE, et al. Morphometric evaluation of gastric antral atrophy: improvement after cure of Helicobacter pylori infection. Am J Gastroenterol 2001;96:3281-7.

110. Ito M, Haruma K, Kamada T, Mihara M, Kim S, Kitadai Y, et al. Helicobacter pylori eradication therapy improves atrophic gastritis and intestinal metaplasia: a 5-year prospective study of patients with atrophic gastritis. Aliment Pharmacol Ther 2002; 16:1449-56.

111. Annibale B, Di Giulio E, Caruana P, Lahner E, Capurso G, Bordi 
C, et al. The long-term effects of cure of Helicobacter pylori infection on patients with atrophic body gastritis. Aliment Pharmacol Ther 2002;16:1723-31.

112. Yamada $\mathrm{T}$, Miwa $\mathrm{H}$, Fujino $\mathrm{T}$, Hirai $\mathrm{S}$, Yokoyama $\mathrm{T}$, Sato $\mathrm{N}$. Improvement of gastric atrophy after Helicobacter pylori eradication therapy. J Clin Gastroenterol 2003:36:405-10.

113. Iacopini F, Consolazio A, Bosco D, Marcheggiano A, Bella A, Pica $\mathrm{R}$, et al. Oxidative damage of the gastric mucosa in Helicobacter pylori positive chronic atrophic and nonatrophic gastritis, before and after eradication. Helicobacter 2003;8:503-12.

114. Kamada T, Haruma K, Hata J, Kusunoki H, Sasaki A, Ito M, et al. The long-term effect of Helicobacter pylori eradication therapy on symptoms in dyspeptic patients with fundic atrophic gastritis. Aliment Pharmacol Ther 2003;18:245-52.

115. Wambura C, Aoyama N, Shirasaka D, Kuroda K, Maekawa S, Ebara $\mathrm{S}$, et al. Influence of gastritis on cyclooxygenase-2 expression before and after eradication of Helicobacter pylori infection. Eur J Gastroenterol Hepatol 2004;16:969-79.

116. Lahner E, Bordi C, Cattaruzza MS, Iannoni C, Milione M, Delle Fave G, et al. Long-term follow-up in atrophic body gastritis patients: atrophy and intestinal metaplasia are persistent lesions irrespective of Helicobacter pylori infection. Aliment Pharmacol Ther 2005;22:471-81.

117. Lu B, Chen MT, Fan YH, Liu Y, Meng LN. Effects of Helicobacter pylori eradication on atrophic gastritis and intestinal metaplasia: a 3-year follow-up study. World J Gastroenterol 2005;11:6518-20.

118. Kamada T, Hata J, Sugiu K, Kusunoki H, Ito M, Tanaka S, et al. Clinical features of gastric cancer discovered after successful eradication of Helicobacter pylori: results from a 9-year prospective follow-up study in Japan. Aliment Pharmacol Ther 2005;21:1121-6

119. Toyokawa T, Suwaki K, Miyake Y, Nakatsu M, Ando M. Eradication of Helicobacter pylori infection improved gastric mucosal atrophy and prevented progression of intestinal metaplasia, especially in the elderly population: a long-term prospective cohort study. J Gastroenterol Hepatol 2010;25:544-7.

120. Kim SG, Jung HK, Lee HL, Jang JY, Lee H, Kim CG, et al; Korean College of Helicobacter and Upper Gastrointestinal Research. Guidelines for the diagnosis and treatment of Helicobacter pylori infection in Korea, 2013 revised edition. Korean J Gastroenterol 2013;62:3-26.

121. Asaka M, Kato M, Takahashi S, Fukuda Y, Sugiyama T, Ota H, et al; Japanese Society for Helicobacter Research. Guidelines for the management of Helicobacter pylori infection in Japan: 2009 revised edition. Helicobacter 2010;15:1-20.
122. Chinese Society of Gastroenterology, Chinese Study Group on Helicobacter pylori, Liu WZ, Xie Y, Cheng H, Lu NH, Hu FL, et al. Fourth Chinese National Consensus Report on the management of Helicobacter pylori infection. J Dig Dis 2013;14:211-21.

123. Asaka M. A new approach for elimination of gastric cancer deaths in Japan. Int J Cancer 2013;132:1272-6.

124. Wong BC, Lam SK, Wong WM, Chen JS, Zheng TT, Feng RE, et al; China Gastric Cancer Study Group. Helicobacter pylori eradication to prevent gastric cancer in a high-risk region of China: a randomized controlled trial. JAMA 2004:291:187-94.

125. Everett SM, Axon AT. Early gastric cancer in Europe. Gut 1997:41:142-50.

126. Gotoda T. Endoscopic resection of early gastric cancer. Gastric Cancer 2007;10:1-11

127. Hamashima C, Shibuya D, Yamazaki H, Inoue K, Fukao A, Saito $\mathrm{H}$, et al. The Japanese guidelines for gastric cancer screening. Jpn J Clin Oncol 2008:38:259-67.

128. National Cancer Control Programs in Korea. J Korean Med Sci 2007;22:S3-4.

129. Mori Y, Arita T, Shimoda K, Yasuda K, Yoshida T, Kitano S. Effect of periodic endoscopy for gastric cancer on early detection and improvement of survival. Gastric Cancer 2001;4:132-6.

130. Yoon H, Kim N, Lee HS, Shin CM, Park YS, Lee DH, et al. Effect of endoscopic screening at 1-year intervals on the clinicopathologic characteristics and treatment of gastric cancer in South Korea. J Gastroenterol Hepatol 2012;27:928-34.

131. Chung SJ, Park MJ, Kang SJ, Kang HY, Chung GE, Kim SG, et al. Effect of annual endoscopic screening on clinicopathologic characteristics and treatment modality of gastric cancer in a high-incidence region of Korea. Int J Cancer 2012;131:2376-84.

132. Correa P, Fontham ET, Bravo JC, Bravo LE, Ruiz B, Zarama G, et al. Chemoprevention of gastric dysplasia: randomized trial of antioxidant supplements and anti-Helicobacter pylori therapy. J Natl Cancer Inst 2000;92:1881-8.

133. Cao DZ, Sun WH, Ou XL, Yu Q, Yu T, Zhang YZ, et al. Effects of folic acid on epithelial apoptosis and expression of Bcl-2 and p53 in premalignant gastric lesions. World J Gastroenterol 2005;11:1571-6.

134. Zullo A, Rinaldi V, Hassan C, Diana F, Winn S, Castagna G, et al. Ascorbic acid and intestinal metaplasia in the stomach: a prospective, randomized study. Aliment Pharmacol Ther 2000;14: 1303-9.

135. Bjelakovic G, Nikolova D, Simonetti RG, Gluud C. Antioxidant supplements for prevention of gastrointestinal cancers: a systematic review and meta-analysis. Lancet 2004:364:1219-28. 